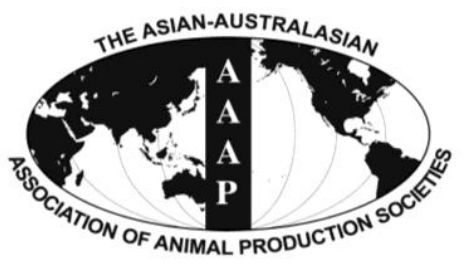

Asian-Aust. J. Anim. Sci.

Vol. 26, No. 4 : 545-551 April 2013

http://dx.doi.org/10.5713/ajas.2012.12502

Www.ajas.info

pISSN $1011-2367$ elSSN 1976-5517

\title{
Development of Gut Microbiota in a Mouse Model of Ovalbumin-induced Allergic Diarrhea under Sub-barrier System
}

\author{
Juan-Hong Wang, Song-Wei Fan and Wei-Yun Zhu* \\ Laboratory of Gastrointestinal Microbiology, Nanjing Agricultural University, Nanjing 210095, China
}

\begin{abstract}
This study aimed to present a mouse model of ovalbumin (OVA) induced allergic diarrhea under a sub-barrier system and investigate the development of gut microbiota in this model. Male BALB/c mice were systemically sensitized with OVA or shamsensitized with saline, and followed by oral OVA intubation, leading to OVA-specific acute diarrhea. Compared with sham-sensitized mice, sera OVA-specific IgG1 and total IgE in OVA-sensitized mice were dramatically elevated, and the number of mast cells was greatly increased in the jejunum of the OVA-sensitized mice. Principle component analysis of the DGGE profile showed that samples from group of OVA-sensitized mice and group of sham-sensitized mice were scattered into two different regions. Real-time PCR analysis showed that the number of 16S rRNA gene copies of Lactobacillus in the colon of OVA-sensitized mice decreased significantly, while there was no significant difference in the number of Bifidobacterium and total bacteria. In conclusion, OVA-specific allergic diarrhea was successfully induced under a sub-barrier system, and changes of allergic reactions during induction was coupled with changes in gut microbiota, especially the number of colonic Lactobacillus, but the role of gut microbiota in the development of food allergic reactions needs to be further evaluated. (Key Words: Ovalbumin, BALB/c mice, Allergy, Diarrhea, Gut Microbiota)
\end{abstract}

\section{INTRODUCTION}

Food allergies have become increasingly prevalent during the past few decades. It was recently reported that up to $6 \%$ of young children and $4 \%$ of adults are affected by food allergies (Sicherer et al., 2006). Cumulative evidences have revealed that there was a close relationship between the development of allergic diseases and the imbalance of intestinal microbiota. Björkstén et al. (1999) showed that the allergic children harbored lower counts of lactobacilli and bifidobacteria, but higher counts of coliforms and Staphylococcus aureus, as compared to non-allergic children. Sjögren et al. (2009) also suggested that children who developed allergy were significantly less colonization of lactobacilli and Bifidobacterium adolescentis during the first 2 months of age. Johansson et al. (2011) found that the colonization of infants gut by a group of lactobacilli reduces the risk of allergy at 5 years of age despite these children had allergic heredity. Therefore, the balance of gut microbiota plays an important role in the prevention of allergic diseases.

Recently, developments in mouse models of food

\footnotetext{
* Corresponding Author: Wei-Yun Zhu. Tel: +86-25-84395523, Fax: +86-25-84395314, E-mail: zhuweiyun@njau.edu.cn Submitted Sept. 14, 2012; Accepted Dec. 14, 2012; Revised Jan. 16, 2013
}

allergy have provided the new tools to better understand this disease. Animal models of food allergy have been used to explore mechanisms of the development of sensitization to food proteins as well as immunologic mechanisms of adverse reactions to allergen re-exposure (Kweon et al., 2000; Forbes et al., 2008; Brandt et al., 2009). However, little information was available on the gut microbiota change during the development of allergy model. Furthermore, all these models were developed under barrier systems, such as SPF condition, which are expensive to establish and maintain. Therefore, in this study, we have used a mouse model of ovalbumin-induced allergic diarrhea according to Brant et al. (2003) under a sub-barrier system, which is in line with international standard and having low cost, and investigated the development of gut microbiota during the allergic diarrhea induction, aiming to gain further insight into the relationship between the gut microbiota and allergy development and provide basic knowledge for the prevention of food allergy.

\section{MATERIAL AND METHODS}

\section{Animals and experimental design}

Twenty four male BALB/c mice (18 to $22 \mathrm{~g}, 6$ to 8 week old) obtained from Nanjing Jinling Hospital (Nanjing, 
China) were housed under sub-barrier system and allowed free access to food and water. Mice were randomly allocated to two groups, OVA-sensitized treatment group and sham-sensitized control group ( $\mathrm{n}=12$ /group), after one week of adaptive phase. All experimental protocols were approved by the Animal Studies Committee of Nanjing Jinling Hospital.

\section{Sub-barrier system}

Laminar flow cabinets and super-clean bench in the laboratory were used for animal feed and experimental manipulation respectively during the whole experiment. Water, cage and beddings were sterilized by autoclaving. Feed were sterilized by radiation. In addition, walls, floors and others in the laboratory were fully cleaned and disinfected according to the requirement of sterile room.

\section{Induction of allergic diarrhea}

Mice were sensitized and challenged as previously by Brant et al. (2003). Briefly, mice in treatment group were sensitized to OVA (grade v, Sigma) by intraperitoneal injection of $100 \mu \mathrm{g}$ of OVA in alum on d 0 and d 14, while mice in control group were sham-sensitized using saline, followed by intragastric feeding of $50 \mathrm{mg}$ of OVA in sterile phosphate buffer saline (PBS, $0.1 \mathrm{~mol} / \mathrm{L}, \mathrm{pH} 7.4$ ) on days $28,30,32,34,36$ and 38. Diarrhea was assessed by visually monitoring mice for up to one hour following intragastric challenge. Mice showing profuse liquid stool were recorded as developing diarrhea. All mice were sacrificed after the 6th intragastric challenge and samples were collected for further analysis.

\section{Measurement of immunoglobulins}

Serum were processed and frozen at $-80^{\circ} \mathrm{C}$ until analysis. Serum OVA-specific IgG1 levels were determined by enzyme linked immunosorbent assay (ELISA). In brief, wells were coated with $100 \mu \mathrm{g} / \mathrm{ml}$ OVA and blocked with $5 \%$ skim milk in water $(\mathrm{w} / \mathrm{v})$. Plates were washed with $0.05 \%$ Tween-20 in PBS and serial dilutions of serum samples (diluted 1:100,000 and then serially diluted 1:2) were added. After one-hour incubation, plates were washed and horseradish peroxidase-conjugated anti-mouse IgG1
$(1: 1,000)$ (A90-105P, Bethyl Laboratories, Inc) was added. Finally, $100 \mu \mathrm{l}$ of o-phenylenediamine (0688, Amresco) substrate solution was added. Colorimetric reaction was stopped with $2 \mathrm{~mol} / \mathrm{L} \mathrm{H}_{2} \mathrm{SO}_{4}$ and the optical density (OD) was read at $492 \mathrm{~nm}$ within $10 \mathrm{~min}$. Data represent mean $\pm \mathrm{SE}$ of the serum dilution required to obtain $\mathrm{OD}=0.6$, because it is in the middle of the linear part of the curve. The level of total $\mathrm{IgE}$ in the serum was measured using an ELISA kit (E-90E, Immunology Consultants Laboratory, Inc). Measurements were performed according to the manufactures' instructions.

\section{Intestinal mast cell quantification}

Jejunum segments were fixed in $4 \%$ paraformaldehyde (w/v) and paraffin embedded for section and histological assessment. Mast cells were detected by chloroacetate esterase (CAE) staining according to published protocols of mast cell detection (Beckstead et al., 1981). The $5 \mu \mathrm{m}$ sections were stained for CAE-positive mucosal mast cells and lightly counterstained with hematoxylin. Five random mice per group and at least three random sections per mouse were analyzed. The numbers of stained cells in a high-power field area $(\times 200)$ were counted using Image-pro Plus 6.0 software.

\section{DNA extraction and PCR amplification}

Total DNA was extracted from each colonic content sample according to a bead-beating method using a minibead beater (Biospec Products, Bartlesville, OK) and followed by phenol-chloroform extraction (Zoetendal et al., 1998). DNA was then precipitated with ethanol and pellets were dissolved in $50 \mu \mathrm{l}$ of TE. Primers U968-GC and L1401 (see Table 1 for all the primers used in this study) (Nübel et al., 1996) were used to amplify the V6 to V8 variable regions of the bacterial $16 \mathrm{~S}$ rRNA gene. PCR amplification was performed using the following program: $94^{\circ} \mathrm{C}$ for $5 \mathrm{~min}$, and 35 cycles of $94^{\circ} \mathrm{C}$ for $30 \mathrm{~s}, 56^{\circ} \mathrm{C}$ for 20 $\mathrm{s}, 68^{\circ} \mathrm{C}$ for $40 \mathrm{~s}$ and $68^{\circ} \mathrm{C}$ for a 7 -min final extension.

\section{DGGE analysis}

PCR amplicons obtained from V6 to V8 regions of $16 \mathrm{~S}$ rRNA genes were separated by DGGE according to the

Table 1. List of primers used in this study

\begin{tabular}{lclc}
\hline Target Group & Primer & \multicolumn{1}{c}{ Sequence 5'-3' } & Reference \\
\hline Total bacteria & U968GC & CGCCCGGGGCGCGCCCCGGGCGGGGCGGGGGC & Nübel et al., 1996 \\
& & ACGGGGGGAACGCGAAGAACCTTAC & Nübel et al., 1996 \\
& L1401 & CGGTGTGTACAAGACCC & Suzuki et al., 2000 \\
& Bact1369 & CGGTGAATACGTTCYCGG & Suzuki et al., 2000 \\
Lactobacillus & Prok1492 & GGWTACCTTGTTACGACTT & Khafipour et al., 2009 \\
& Ulac16S1F & AGCAGTAGGGAATCTTCCA & Khafipour et al., 2009 \\
Bifidobacterium & Ulac16S1R & ATTCCACCGCTACACATG & Matsuki et al., 2004 \\
& g-Bifid-F & CTCCTGGAAACGGGTGG & Matsuki et al., 2004 \\
\hline
\end{tabular}


specifications of Muyzer et al. (1993) using a Dcode TM system (Bio-Rad, Hercules, CA, USA). DGGE was performed in $8 \%$ polyacrylamide gels containing $37.5: 1$ acrylamide-bisacrylamide and a denaturing gradient of $40 \%$ to $53 \%$. Electrophoresis was initiated by pre-running for 10 min at $200 \mathrm{~V}$ and subsequently continued at a fixed voltage of $85 \mathrm{~V}$ for $12 \mathrm{~h}$. Gels were stained with $\mathrm{AgNO}_{3}$ after completion of electrophoresis (Sanguinetti et al., 1994). DGGE gels were scanned using a GS-800 Calibrated Densitometer (Bio-Rad) and principle component analysis (PCA) was performed using SIMCAP+(12) software.

Real-time PCR quantification of total bacteria, Lactobacillus and Bifidobacterium

Real-time PCR was performed on an Applied Biosystems 7300 Real-time PCR System (Applied Biosystems, California, USA). A reaction mixture $(20 \mu \mathrm{l})$ consisted of $10 \mu$ of IQ SYBR Green Supermix (Bio-Rad, California, USA), $0.2 \mu \mathrm{M}$ of each primer set and $1 \mu \mathrm{l}$ of the template DNA. Standard curves were generated with 10fold serial dilutions of 16S rRNA genes amplified from the respective target strains. The concentration of $16 \mathrm{~S}$ rRNA gene abundance was plotted against the CT value. Universal primers, Bact1369 and Prok1492 (Suzuki et al., 2000), were used to estimate the total number of copies of the bacterial 16S rRNA gene in each sample. Lactobacillus and Bifidobacterium were quantified using the primers Ulac16S1F/Ulac16S1R (Khafipour et al., 2009) and gBifid-F/g-Bifid-R (Matsuki et al., 2004) respectively. Samples from five random mice per group were analyzed.

\section{Statistics}

Statistical analysis was conducted using SPSS 16.0 software. The $x^{2}$ test was used to compare the frequency of diarrhea, while independent-samples $\mathrm{T}$ test was used to analyze other data. p-values $<0.05$ were considered significant. Data are represented as means \pm SE.

\section{RESULTS}

\section{Induction of intestinal allergic symptom}

The stool of OVA-sensitized mice began to shift from normal to a profuse liquid stool after the 4th OVA challenge. In addition, the liquid stool was observed following OVAinduced diarrhea contrasts with the solid pellets seen in the distal colon of normal mice. Figure 1 shows the time course of changes in the number of mice affected with diarrhea. Diarrhea was observed after 4th oral administrations of OVA to the OVA-sensitized mice, and the incidence of diarrhea continued to increase by the end of the experiment. However, repeated oral administration of OVA in mice with sham-sensitization failed to induce any signs of diarrhea. In particular, OVA-sensitized mice showed a significantly

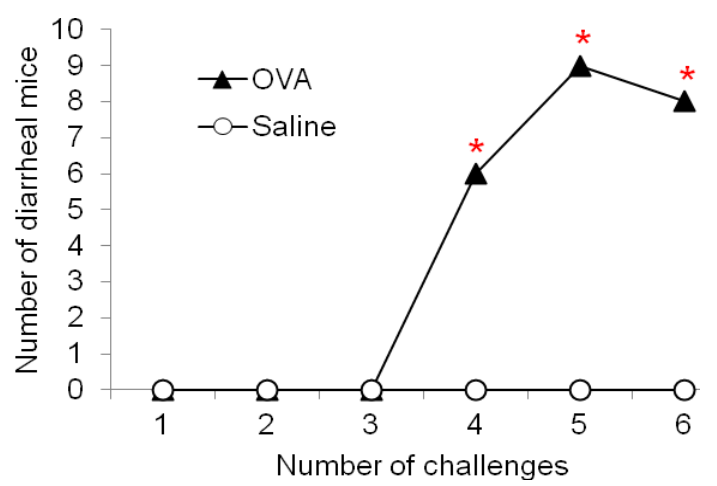

Figure 1. Changes in time course of the number of diarrheal mice. Diarrhea occurrence of OVA-sensitized $(\boldsymbol{\Delta})$ and saline-sensitized (०) mice was assessed after 1st to 6th OVA challenges. ( $n=12$ mice/group; * $\mathrm{p}<0.05)$.

higher incidence of diarrhea as compared with those without OVA-sensitization after 4 th to 6th challenges $\left(x^{2}\right.$ test, $\mathrm{p}<0.05)$.

\section{OVA-specific IgG1 and total IgE in the sera}

The level of OVA-specific IgG1 in the sera was measured on $\mathrm{d} 21$ (one week after two sensitizations) and $\mathrm{d}$ 38 (after 6th challenge). As shown in Figure 2A, sera levels

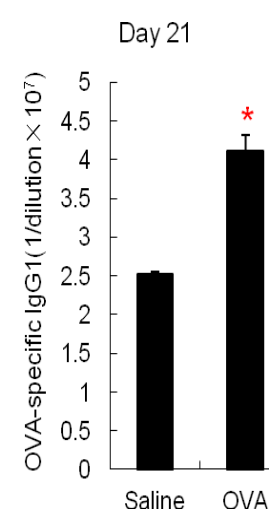

(A)

(C)

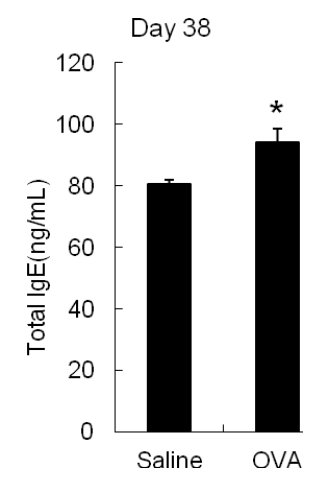

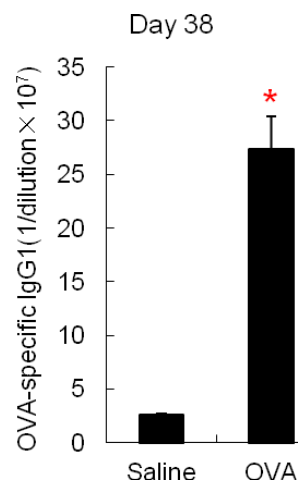

(B)
Figure 2. Serum OVA-specific IgG1 and total IgE levels. OVAspecific IgG1 were measured on d 21 (A) and d 38 (B), total IgE were determined on d $38(\mathrm{C})$. $(\mathrm{n}=12$ mice/group; mean $\pm \mathrm{SE}$; $* \mathrm{p}<0.05$ ) 
of OVA-specific IgG1 was significantly higher in OVAsensitized mice compared with sham-sensitized mice after sensitization alone $(p<0.05)$. Following allergen-induced diarrhea, OVA-specific IgG1 in OVA-sensitized mice had a further increase, which was approximately 10-fold greater than that of sham-sensitized mice (Figure 2B). In addition, total IgE sera titers after OVA challenges were significantly higher in OVA-sensitized mice compared with shamsensitized mice (Figure 2C).

\section{Mast cell infiltration}

Figure 3 showed that the jejunum of OVA-sensitized mice contained highly increased levels of mast cells compared with sham-sensitized control mice and mast cells in jejunum of OVA-sensitized mice were predominantly localized to lamina propria region (Figure $3 \mathrm{~A}$ and $\mathrm{B}$ ). Furthermore, as shown in Figure 3C, mast cell levels in the jejunum of OVA-sensitized mice were significantly higher than that of sham-sensitized mice $(\mathrm{p}<0.05)$.

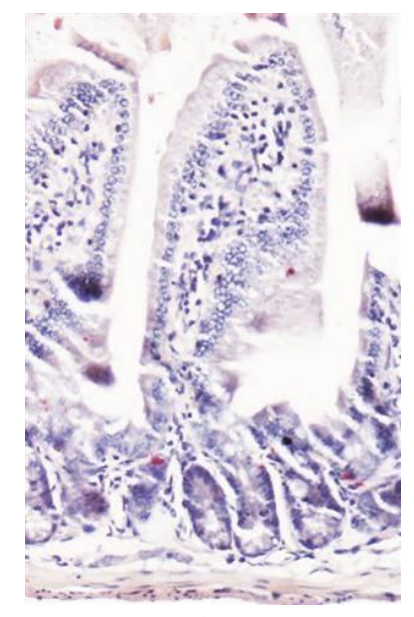

A

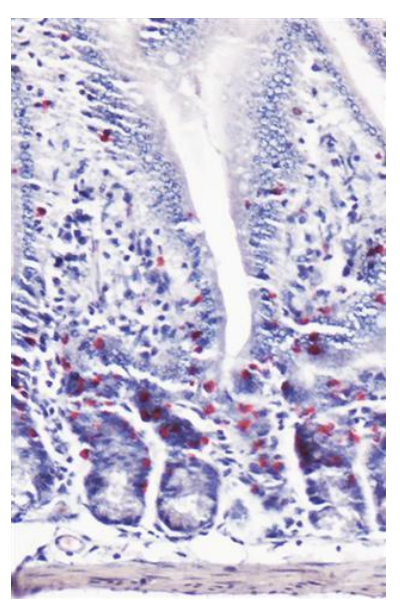

$\mathrm{B}$

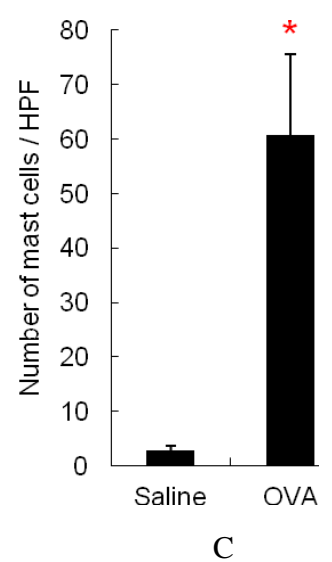

Figure 3. Mucosal mast cell responses. Representative fields (original magnification, $\times 200$ ) of saline-sensitized (A) or OVAsensitized (B) jejunum sections stained with chloroacetate esterase. (C) Mast cell levels were calculated by Image-Pro Plus 6.0 software. $(n=5$ mice/group; mean $\pm S E ; * p<0.05)$.

\section{Analysis of bacteria diversity in colon samples using PCR-DGGE}

Figure 4A showed no specific band appeared or disappeared on the bacteria DGGE profiles of the content of colon. Principle component analysis for the DGGE profile (Figure 4B) showed that samples from group of OVAsensitized mice and group of sham-sensitized mice were scattered into two different regions, indicating certain intertreatment variation.

\section{Quantitative real-time PCR analysis}

As shown in Figure 5, the concentration of Lactobacillus 16S rRNA gene copies was significantly lower in colon samples of mice with OVA-sensitization than those of sham-sensitized mice $(p<0.05)$. However, no significant changes in the number of total bacteria and Bifidobacterium in the colonic content were found between OVA-sensitized mice and sham-sensitized mice.

\section{DISCUSSION}

This study presented a mouse model of OVA-induced allergic diarrhea according to Brant et al. (2003) under sub-
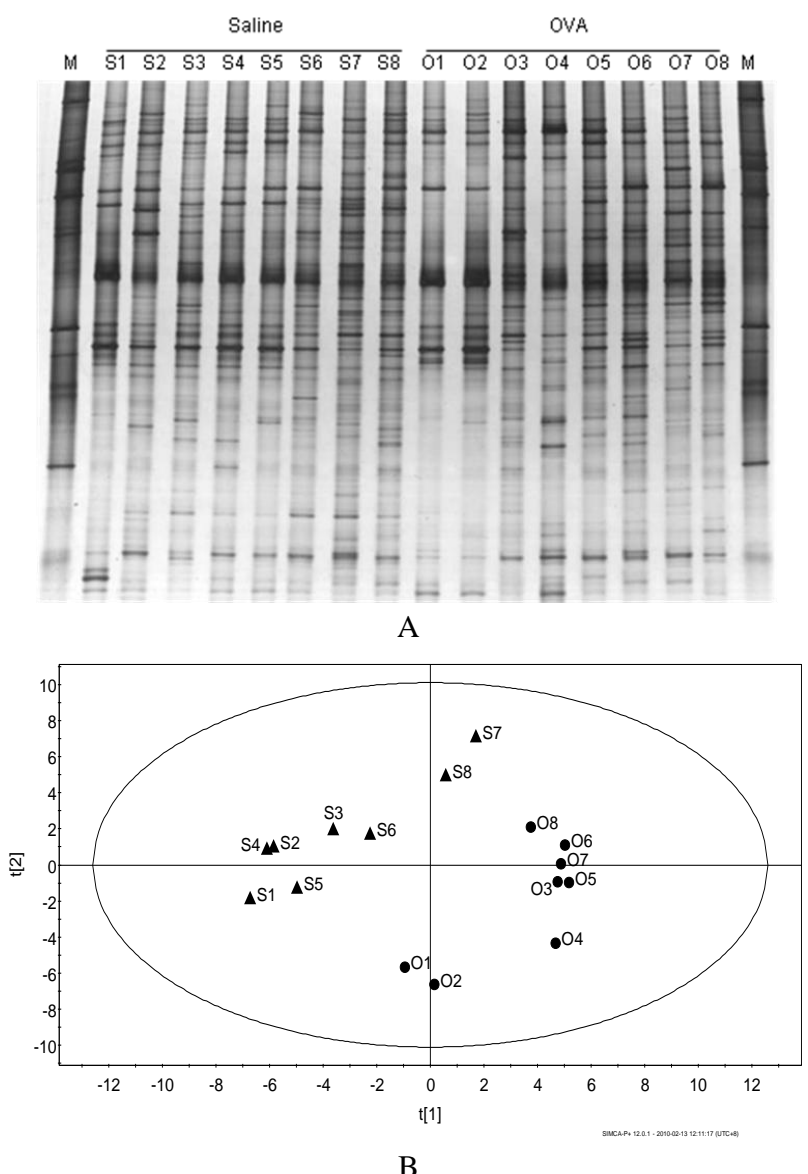

Figure 4. PCA Analysis (B) of DGGE profiles (A) for total bacteria in the colon of saline sensitized (S1 to S8, $\mathbf{\Delta}$ ) and OVA sensitized mice $(\mathrm{O} 1$ to $\mathrm{O} 8, \bullet)$. 


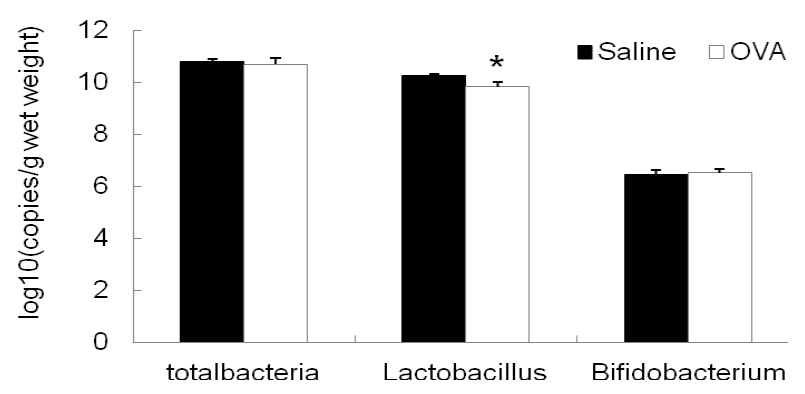

Figure 5. Quantitative real-time PCR Analysis of total bacteria, Lactobacillus and Bifidobacterium in the colon of saline sensitized (घ) and OVA sensitized ( $\square)$ mice. ( $n=5$ mice/group; mean \pm SE; $* \mathrm{p}<0.05)$.

barrier system. The hygiene hypothesis (Strachan et al., 1989) of allergic diseases indicates that strict environmental facilities, such as SPF condition, are required to induce Th2 responses. However, SPF conditions are expensive to establish and maintain. Therefore, a facility, which is in line with international standard and having low cost, instead of SPF condition is need to establish. Previous studies have showed that laminar flow cabinet in common laboratory animal facility can provide a local SPF condition and can be successfully used to breed nude mice ( $\mathrm{Li}$ et al., 2003) and diabetes Scid mice (Li et al., 2005) which are both immunedeficient mice. In this study, BALB/c mice were maintained in the laminar flow cabinet and found to successfully develop diarrhea after repeat OVA challenges, although diarrhea occurred in this study was later and less sever. These data suggested that an acute allergic response could be induced in these mice under sub-barrier system.

We further demonstrated that diarrhea occurred in this study was allergic diarrhea. Food allergies are adverse immunological responses to food proteins. Allergens generally induce a shift in the Th1/Th2 balance toward Th2 immunity (Helm et al., 2003). In the Th2-biased cytokine microenvironment, IgE is produced by $\mathrm{B}$ cells and binds to its receptor on mast cells. Upon subsequent ingestion, antigenic fragments may interact directly with receptorbound IgE on mast cells and trigger the release of the preformed and newly formed chemical mediators responsible for clinical symptoms (Prioult et al., 2005). Previously, Brant et al. (2003) observed that oral OVAinduced food allergic diarrhea is largely mast cell and IgE dependent. In this study, we also found that levels of OVAspecific IgG1 and total IgE in sera as well as the number of mast cells in jejunum greatly increased after repeat challenges. These data suggested that diarrhea developed in this study was allergic diarrhea.

Results of this study led to an important discovery that OVA-sensitized mice and sham-sensitized mice were discriminative for colonic microbial populations after the induction of diarrhea. Previous studies have showed that gut microbiota composition might be involved in allergic diseases. Wang et al. (2008) showed that there was a reduction in diversity of fecal microbiota in the early stage of infants with atopic eczema. In this study, no significant difference in diversity of colonic microbiota was found between healthy mice and diarrheal mice. However, principle component analysis of DGGE profile showed that samples from group of OVA-sensitized mice and group of sham-sensitized mice were scattered into two different regions, indicating certain inter-treatment variation.

Another finding of this investigation was that numbers of Lactobacillus in the colon of mice decreased as allergic diarrhea occurred. Previously, many studies have revealed that numbers of lactobacilli and bifidobacteria in the intestine of allergic disorders reduced as allergic reactions develop, while numbers of coliforms and Staphylococcus aureus increased (Bottcher et al., 2000; Björkstén et al., 2001). Supplementation of lactobacilli and bifidobacteria improved the balance of the intestinal microbiota, which was beneficial for the prevention of allergic diseases, including atopic dermatitis, asthma, allergic rhinitis and allergic diarrhea (Forsythe et al., 2007; Sunada et al., 2007; Schouten et al., 2009; Won et al., 2011). In this study, our results showed that copies of Lactobacillus 16S rRNA gene in colon samples of OVA-sensitized mice was greatly reduced, suggesting a close relationship between development of allergic diarrhea and reduction of Lactobacillus in the colon. At present, increasing evidences suggested that some cell components in probiotics such as immunostimulatory sequence oligodeoxynucleotides (ISSODNs) suppressed the Th2 immune responses (Takahashi et al., 2006; Kim et al., 2008) or inhibited the IgE production (Iliev et al., 2008; Hougee et al., 2010), resulting in the alleviation of allergic diseases. In addition, it was reported that mast cells express Toll-like receptor (TLR) (Bischoff et al., 2007), suggesting that gut microbes may interact directly with TLR on mast cells and regulate allergic responses (Bashir et al., 2004). However, further studies are required to uncover the mechanisms of the allergypreventing effect of gut microbiota.

\section{CONCLUSIONS}

In conclusion, this study presented a mouse model of OVA-induced allergic diarrhea under sub-barrier system and showed that the number of colonic Lactobacillus reduced after induced diarrhea. These results suggested that food allergic diarrhea is associated with colonic Lactobacillus and that the reduction of colonic Lactobacillus numbers may be an important factor in the development of food allergic diseases. But further studies 
are warranted to evaluate the role of gut microbiota in the development of food allergic reactions.

\section{ACKNOWLEDGEMENTS}

This work was supported by the Natural Science Foundation of China (30810103909).

\section{REFERENCES}

Bashir, M. E., S. Louie, H. N. Shi and C. Nagler-Anderson. 2004. Toll-like receptor 4 signaling by intestinal microbes influences susceptibility to food allergy. J. Immunol. 172:6978-6987.

Beckstead, J. H., P. S. Halverson, C. A. Ries and D. F. Bainton. 1981. Enzyme histochemistry and immunohistochemistry on biopsy specimens of pathologic human bone marrow. Blood. 57:1088-1098.

Bischoff, S. C. and S. Kramer. 2007. Human mast cells, bacteria and intestinal immunity. Immunol. Rev. 217:329-337.

Björkstén, B., P. Naaber, E. Sepp and M. Mikelsaar. 1999. The intestinal microflora in allergic Estonian and Swedish twoyear-old-children. Clin. Exp. Allergy 29:342-346.

Björkstén, B., E. Sepp, K. Julge, T. Voor and M. Mikelsaar. 2001. Allergy development and the intestinal microflora during the first year of life. J. Allergy Clin. Immun. 108:516-520.

Bottcher, M. F., E. K. Nordin, A. Sandin, T. Midtvedt and B. Bjorksten. 2000. Microflora-associated characteristics in faeces from allergic and non-allergic infants. Clin. Exp. Allergy 30:1590-1596.

Brandt, E. B., R. T. Strait, D. Hershko, Q. Wang, E. E. Muntel, T. A. Scribner, N. Zimmermann, F. D. Finkelman and M. E. Rothenberg. 2003. Mast cells are required for experimental oral allergen-induced diarrhea. J. Clin. Invest. 2:1666-1677.

Brandt, E. B., A. Munitz, T. Orekov, M. K. Mingler, M. McBride, F. D. Finkelman and M. E. Rothenberg. 2009. Targeting IL4/IL-13 signaling to alleviate oral allergen-induced diarrhea. J. Allergy Clin. Immun. 123:53-58.

Forbes, E. E., K. Groschwitz, J. P. Abonia, E. B. Brandt, E. Cohen, C. Blanchard, R. Ahrens, L. Seidu, A. McKenzie, R. Strait, F. D. Finkelman, P. S. Foster, K. I. Matthaei, M. E. Rothenberg and S. P. Hogan. 2008. IL-9- and mast cell-mediated intestinal permeability predisposes to oral antigen hypersensitivity. J. Exp. Med. 205:897-913.

Forsythe, P., M. D. Inman and J. Bienenstock. 2007. Oral treatment with live Lactobacillus reuteri inhibits the allergic airway response in mice. Am. J. Respir. Crit. Care Med. 175:561-569.

Helm, R. M., R. W. Ermel and O. L. Frick. 2003. Nonmurine animal models of food allergy. Environ. Health Perspect. 111:239-244.

Hougee, S., A. J. Vriesema, S. C. Wijering, L. M. Knippels, G. Folkerts, F. P. Nijkamp, J. Knol and J. Garssen. 2010. Oral treatment with probiotics reduces allergic symptoms in ovalbumin-sensitized mice: a bacterial strain comparative study. Int. Arch. Allergy Immunol. 151:107-117.

Iliev, I. D., M. Tohno, D. Kurosaki, T. Shimosato, F. He, M. Hosoda, T. Saito and H. Kitazawa. 2008. Immunostimulatory oligodeoxynucleotide containing TTTCGTTT motif from Lactobacillus rhamnosus GG dna potentially suppresses OVAspecific IgE production in mice. Scand. J. Immunol. 67:370376

Johansson, M. A., Y. M. Sjögren, J. O. Persson, C. Nilsson and E. Sverremark-Ekström. 2011. Early colonization with a group of Lactobacilli decreases the risk for allergy at five years of age despite allergic heredity. PLoS One. 6:e23031.

Khafipour, E., S. Li, J. C. Plaizier and D. O. Krause. 2009. Rumen microbiome composition determined using two nutritional models of subacute ruminal acidosis. Appl. Environ. Microbiol. 75:7115-7124.

Kim, J. Y., Y. O. Choi and G. E. Ji. 2008. Effect of oral probiotics (Bifidobacterium lactis AD011 and Lactobacillus acidophilus AD031) administration on ovalbumin-induced food allergy mouse model. J. Microbiol. Biotechnol. 18:1393-1400.

Kweon, M. N., M. Yamamoto, M. Kajiki, I. Takahashi and H. Kiyono. 2000. Systemically derived large intestinal CD4(+) Th2 cells play a central role in STAT6-mediated allergic diarrhea. J. Clin. Invest. 106:199-206.

Li, F., J. Z. Wu and Y. Li. 2003. Experience of breeding nude mice in laminar flow cabinet. Lab. Anim. Sci. Adm. 20:52-54.

Li, H. and W. Chen. 2005. Breeding diabetes scid mice with streamline cabinet. Lab. Anim. Sci. Adm. 22:54-55.

Matsuki, T., K. Watanabe, J. Fujimoto, T. Takada and R. Tanaka. 2004. Use of 16S rRNA gene-targeted group-specific primers for real-time PCR analysis of predominant bacteria in human feces. Appl. Environ. Microbiol. 70:7220-7228.

Muyzer, G., E. C. de Waal and A. G. Uitterlinden. 1993. Profiling of complex microbial populations by denaturing gradient gel electrophoresis analysis of polymerase chain reactionamplified genes coding for 16S rRNA. Appl. Environ. Microbiol. 59:695-700.

Nübel, U., B. Engelen, A. Felske, J. Snaidr, A. Wieshuber, R. I. Amann, W. Ludwig and H. Backhaus. 1996. Sequence heterogeneities of genes encoding 16S rRNAs in Paenibacillus polymyxa detected by temperature gradient gel electrophoresis. J. Bacteriol.178:5636-5643.

Prioult, G. and C. Nagler-Anderson. 2005. Mucosal immunity and allergic responses: lack of regulation and/or lack of microbial stimulation. Immunol. Rev. 206:204-218.

Sanguinetti, C. J., D. Dias Neto and A. J. Simpson. 1994. Rapid silver staining and recovery of PCR products separated on polyacrylamide gels. Biotechniques 17:914-921.

Schouten, B., B. C. van Esch, G. A. Hofman, S. A. van Doorn, J. Knol, A. J. Nauta, J. Garssen, L. E. Willemsen and L. M. Knippels. 2009. Cow milk allergy symptoms are reduced in mice fed dietary synbiotics during oral sensitization with whey. J. Nutr. 139:1398-1403.

Sicherer, S. H. and H. A. Sampson. 2006. Food allergy. J. Allergy Clin. Immunol. 117:S470-S475.

Sjögren, Y. M., M. C. Jenmalmw, M. F. Böttcher, B. Björkstén and E. Sverremark-Ekström. 2009. Altered early infant gut microbiota in children developing allergy up to 5 years of age. Clin. Exp. Allergy 39:518-526.

Strachan, D. P. 1989. Hay fever, hygiene, and household size. BMJ. 299:1295-1260.

Sunada, Y., S. Nakamura and C. Kamei. 2007. Effects of 
Lactobacillus acidophilus strain L-55 on experimental allergic rhinitis in BALB/c mice. Biol. Pharm. Bull. 30:2163-2166.

Suzuki, M. T., L. T. Taylor and E. F. DeLong. 2000. Quantitative analysis of small-subunit rRNA genes in mixed microbial populations via 5'-nuclease assays. Appl. Environ. Microbiol. 66:4605-4614.

Takahashi, N., H. Kitazawa, N. Iwabuchi, J. Z. Xiao, K. Miyaji, K. Iwatsuki and T. Saito. 2006. Immunostimulatory oligodeoxynucleotide from Bifidobacterium Longum suppresses Th2 immune responses in a murine model. Clin. Exp. Immunol. 145:130-138.
Wang, M., C. Karlsson, C. Olsson, I. Adlerberth, A. E. Wold, D. P. Strachan, P. M. Martricardi, N. Aberg, M. R. Perkin, S. Tripodi, A. R. Coates, B. Hesselmar, R. Saalman, G. Molin and S. Ahrne. 2008. Reduced diversity in the early fecal microbiota of infants with atopic eczema. J. Allergy Clin. Immunol. 121:129-134.

Won, T. J., B. Kim, Y. T. Lim, D. S. Song, S. Y. Park, E. S. Park, D. I. Lee and K. W. Hwang. 2011. Oral administration of Lactobacillus strains from Kimchi inhibits atopic dermatitis in NC/Nga mice. J. Appl. Microbiol. 110:1195-1202.

Zoetendal, E. G., A. D. Akkermans and W. M. De Vos. 1998. Temperature gradient gel electrophoresis analysis of $16 \mathrm{~S}$ rRNA from human fecal samples reveals stable and host-specific communities of active bacteria. Appl. Environ. Microbiol. 64:3854-3859. 